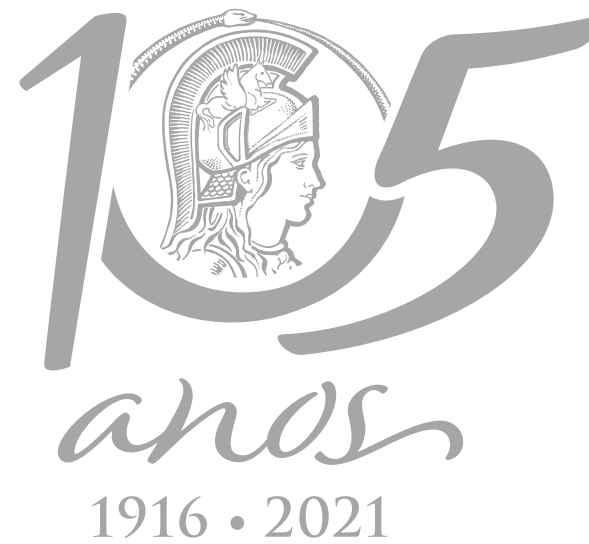

$1916 \cdot 2021$

\title{
CHEMICAL SCIENCES
}

\section{Dereplication by HPLC-ESI-MS and antioxidant activity of phenolic compounds from Banisteriopsis laevifolia (Malpighiaceae)}

\author{
GERSO P. ALEXANDRE, JORGE LUIZ S. SIMÃO, MARIA OLIVIA A. TAVARES, \\ IZABELLA MARIANA S. ZUFFO, STÉPHANIE V. PRADO, JOSEILSON A. DE PAIVA, \\ ABUBAKAR N. MUSTAPHA, ANSELMO E. DE OLIVEIRA, LUCILIA KATO \& \\ VANESSA GISELE P. SEVERINO
}

\begin{abstract}
The genus Banisteriopsis (Malpighiaceae) comprises 77 genera and 1,300 species. Despite efforts to provide detailed information about the chemical wealth of B. laevifolia, this article provides the identification and characterization of compounds from the ethanolic extracts of the leaves and flowers using advanced methodologies which include high-performance liquid chromatography coupled to tandem mass spectrometry, which contribute to the knowledge about compounds present in the genus Banisteriopsis. The dereplication aided by Global Natural Products Social Molecular Networking afforded the identification of seven compounds reported for this species for the first time. A mixture of two known flavonoids and a diterpenoid, 18-hydroxy-ent-halima-1(10),13(E)-dien-15-oic acid, were isolated by conventional separation methods. The elevated 2,2-diphenyl-1-picrylhydrazyl radical scavenging activity observed in some samples was attributed to either the type of extract, the presence of 3,4,5-trihydroxybenzoic acid, or the influence of the substitution pattern and the synergistic effect of the compounds present. Principal Component Analysis was applied to correlate mass spectrometry data with the antioxidant activity of the samples. The high diversity of metabolites found in this study and those which have been reported for Banisteriopsis strongly recommends further investigation into the chemical and biological properties of these species.
\end{abstract}

Key words: Banisteriopsis laevifolia, phenolic compounds, antioxidant activity, molecular networking, dereplication.

\section{INTRODUCTION}

With six biomes, the biodiversity of Brazilian flora is considered the richest in the world. This flora has more than 55 thousand plant species out of which 10 thousand are considered medicinal, aromatic, and useful plants (Batalha \& Ming 2004). The Brazilian Cerrado savanna is endowed with ecosystems that are marked by rich vegetation and plant diversity. It is said to represent the second largest biome in Brazil, especially when considering woody species (Guarim-Neto \& Morais 2003). Families such as Mimosaceae, Fabaceae, Caesalphiniaceae, Poaceae, Asteraceae, Malpighiaceae, and others have been identified in this domain (Klink \& Machado 2005).

The genus Banisteriopsis belongs to the Malpighiaceae family, which is comprised of 77 genera and 1,300 species (92 of these species are mainly distributed in Brazil, Bolivia, Colombia, Ecuador, and Peru), presenting a pantropical 
distribution with the greatest biodiversity in the South American continent (Anderson \& Davis 2010, Wang et al. 2010).

Several research studies related to the biological potential of the genus Banisteriopsis have been reported (Rodrigues \& Carvalho 2001, Frias et al. 2011). Classes of compounds with medicinal indications/therapeutics have been identified in this genus. Research describing dihydrophenanthrenes in B. anisandra and phytohormones and the psychoactive indole alkaloids with $\beta$-carboline structure in $B$. caapi have also been reported. These active hallucinogenic compounds are served in drinks during rituals by the Ayahuasca in occidental countries (Freitas et al. 2015, Schwarz et al. 2003).

The extracts from different species of Banisteriopsis have been acclaimed for a number of therapeutic indications. For instance, B. argyrophylla has been described with anti-inflammatory action; B. campestris is used as diuretic; and B. megaphylla is used for antipyretic activity and for the treatment of pulmonary diseases; while the ethanolic extracts of $B$. anisandra showed an in vitro antimicrobial activity (Pádua et al. 2013, Frias et al. 2011). The chemical compounds from the essential oils extracted from the leaves of $B$. laevifolia showed antimicrobial activity against yeasts of the genus Candida (Nunes et al. 2016). In addition to the established bioactivity and presence of alkaloids and phenolic compounds in B. laevifolia, there are folkloric reports on the uses of the roots in the treatment of ovarian haemorrhage (Rodrigues \& Carvalho 2001). Due to the activity reported for B. laevifolia, the analysis of the antioxidant potential helps to confirm the presence of phenolic compounds in metabolism of this species, as well as contributes to evaluation and selection of substances that have potential to be used as medicinal drugs (Nunes et al. 2016, Alves et al. 2010).
Despite efforts to provide detailed information about the chemical wealth of B. laevifolia species, it has been observed that little is known about the metabolic fingerprinting of the extracts of some parts of this species that have been reported for their marked folkloric indications. In view of this, this article presents the compounds identified and characterized from the ethanolic extracts of the leaves and flowers of $B$. laevifolia. Advanced and adopted/modified methodologies were used which include high-performance liquid chromatography coupled to tandem mass spectrometry (HPLC-MS/MS). In addition, the antioxidant activity of the compounds isolated from the flowers is also reported.

\section{MATERIALS AND METHODS}

\section{Plant Material}

Access to the genetic heritage was registered at the National System of Genetic Resource Management and Associated Traditional Knowledge (SisGen) under code No. A11AE20. Flowers and leaves of B. laevifolia were collected in March 2016 at the Serrinha Reserve (16 43'25"S $\left.49^{\circ} 15^{\prime} 50^{\prime \prime} \mathrm{W}\right)$ located in Goiânia city, state of Goiás, Brazil. The materials were identified by Dr. Aristônio Magalhães Teles and a voucher (UFG60052) was deposited in the herbarium of the Federal University of Goiás (UFG), Brazil.

\section{Equipment}

${ }^{1} \mathrm{H}(500 \mathrm{MHz})$ and ${ }^{13} \mathrm{C}(125 \mathrm{MHz})$ nuclear magnetic resonance (NMR) spectra were obtained on a Bruker Avance III 500 (11,75T). Compound (1) was dissolved in $\mathrm{CDCl}_{3}$ (Sigma-Aldrich, St. Louis, MO, USA) and a mixture of (2) and (3) was dissolved in $\mathrm{CD}_{3} \mathrm{OD}$ (Sigma-Aldrich, St. Louis, MO, USA). HPLC was performed on a Shimadzu apparatus with an LC-18A pump, an SPD-20A detector, a CBM-20A-communications module (Shimadzu), 
and a Rheodyne injector with a loop of 500 $\mu \mathrm{L}$. The liquid chromatography coupled to the high-resolution tandem mass spectrometry (HPLC-ESI-HRMS/MS) system consisted of an Ultimate 3000 HPLC (Thermo Scientific) coupled to a Q-Exactive Orbitrap high-resolution mass spectrometer (Thermo Scientific) controlled by software Xcalibur ${ }^{\top M}$, version 4.2. An H-ESI (heated electrospray ionization) source in negative mode was used for monitoring the compounds by HRFS (high resolution full scan) and in the parallel reaction monitoring (PRM) experiments. An UVVIS spectrophotometer, model Sp 22 Biospectro, was used with glass cells of $1 \mathrm{~cm}$ path length.

\section{Extraction}

The fresh flowers (618 g) were extracted by maceration with ethanol (Merck, Darmstadt, Germany) ( $3 \times 1 \mathrm{~L}$, every 3 days) at room temperature. The material was filtered and then concentrated in a rotary evaporator to obtain the ethanolic extract of flowers (EEF) (49.7 g, 8.0\%). The air-dried leaves (719 $\mathrm{g}$ ) were pulverized in a knife mill, extracted at room temperature with ethanol (EtOH) $(3 \times 3$ L, 3 days each) and filtered. The filtrate was concentrated to yield the ethanolic extract of leaves (EEL) (79.2 g, 11.0\%).

Liquid-liquid extraction was used to fractionate a portion of the EEF (15 g) into the following fractions: hexane (Merck, Darmstadt, Germany) (1.1 g), dichloromethane (Merck, Darmstadt, Germany) (2.8 g), ethyl acetate (Merck, Darmstadt, Germany) (6.4 g), and n-butanol (Merck, Darmstadt, Germany) (3.8 g). Thereafter, a portion of the dichloromethane fraction (480 mg) was subjected to a Sephadex LH-20 (Amersham, Pharmacia Biotech, Little Chalfout, UK) column and eluted with $\mathrm{CH}_{2} \mathrm{Cl}_{2}: \mathrm{CH}_{3} \mathrm{OH}$ (Merck, Darmstadt, Germany) (2:8) to give six subfractions (D1 to D6). Sub-fraction D2 (66.8 mg) was again chromatographed on a Sephadex LH20 column eluted with $\mathrm{CH}_{3} \mathrm{OH}: \mathrm{CH}_{2} \mathrm{Cl}_{2}$ (8:2) to give five sub-fractions (D2.1 to D2.5). Sub-fraction D2.5 availed compound (11) (5 mg). Sub-fraction D3 (72.0 mg) was subjected to silica gel (Merck, Darmstadt, Germany) column chromatography eluted with solvents of increasing polarity [hexane:ethyl acetate (1:0 to 0:1) and ethyl acetate: $\mathrm{CH}_{3} \mathrm{OH}$ (1:0 to 0:1)] to give nine sub-fractions (D3.1 to D3.9). Subfraction D3.9 (11.1 mg) was purified by HPLC using $\mathrm{CH}_{3} \mathrm{OH}: \mathrm{CH}_{2} \mathrm{Cl}_{2}$ (8:2), isocratic mode with a flow rate of $5.0 \mathrm{~mL} \mathrm{~min}{ }^{-1}$, to yield a mixture of compounds (1) and (2) (5.2 mg). The ethyl acetate fraction (3.9 g) was subjected to a Sephadex LH-20 column and eluted with $\mathrm{CH}_{3} \mathrm{OH}: \mathrm{CH}_{2} \mathrm{Cl}_{2}$ (8:2) to yield fourteen sub-fractions (EA1 to EA14). Sub-fraction EA7 (520 mg) was further purified by $\mathrm{HPLC}$ using $\mathrm{CH}_{3} \mathrm{OH}$ : $\mathrm{CH}_{2} \mathrm{Cl}_{2}$ (8:2), isocratic mode with a flow rate of 5.0

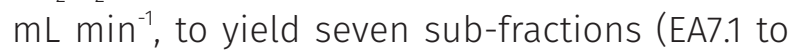
EA7.13). Sub-fraction EA7.11 (95.8 mg) was purified by $\mathrm{HPLC}$ using $\mathrm{CH}_{3} \mathrm{OH}: \mathrm{CH}_{2} \mathrm{Cl}_{2}$ (8:2), isocratic mode with a flow rate of $5.0 \mathrm{~mL} \mathrm{~min}{ }^{-1}$, to yield six subfractions (EA7.11.1 to EA7.11.6).

\section{Mass Spectrometry Data Acquisition}

The both extracts and sub-fractions D3.5, D3.7, EA7.3, EA7.6, EA7.11.1 and EA7.11.4 were subjected to liquid chromatography coupled to the highresolution tandem mass spectrometer (HPLCESI-HRMS/MS) for identification of phenolic compounds, and each sample $(1.0 \mathrm{mg})$ was dissolved in $1.0 \mathrm{~mL}$ of $\mathrm{CH}_{3} \mathrm{OH}$ and filtered through a cellulose acetate filter $(0.45 \mu \mathrm{m})$. The chromatographic separation was carried out using an NST 18 column (4.6 mm × $100 \mathrm{~mm}, 5.0$ $\mu \mathrm{m})$ at $20{ }^{\circ} \mathrm{C}$ with mobile phases of deionized water (A) and acetonitrile (Sigma-Aldrich) (B), both acidified with $0.1 \%$ formic acid (SigmaAldrich). The applied gradient was 50 to 100\% B over 40 minutes, then $100 \%$ B was maintained for 5 minutes at a flow rate of $1.0 \mathrm{~mL} \mathrm{~min}^{-1}$ and a $10 \mu \mathrm{L}$ injection volume. The MS parameters used were as follows: spray voltage $4 \mathrm{kV}$, sheath gas flow rate 30 arbitrary units, auxiliary gas flow 
rate 10 arbitrary units, capillary temperature $350^{\circ} \mathrm{C}$, a uxiliary gas heater temperature $300^{\circ} \mathrm{C}$, S-lens 55 and collision energy offset of $20 \mathrm{eV}$. The samples were analysed by a Data Dependent Acquisition (DDA) method using the HR full-scan experiment set up in the $\mathrm{m} / \mathrm{z}$ range of 150 to $700 \mathrm{Da}$. The precursor ions were selected and subsequently performed by parallel reaction monitoring (PRM) to obtain MS/MS spectra.

\section{Total Phenolic Content}

Total Phenols Content (TPC) was assayed according to the methodology described by Sousa et al. (2007) with modifications by Nunes et al. (2016). 3,4,5-trihydroxybenzoic acid (Sigma-Aldrich, St. Louis, MO, USA) standard solutions (10.0, 20.0, 40.0, 60.0 and $80.0 \mu \mathrm{g}$ $\mathrm{mL}^{-1}$ ) were prepared in $\mathrm{CH}_{3} \mathrm{OH}$ and used to construct a calibration curve. The phenolic content was expressed as milligrams of 3,4,5-trihydroxybenzoic acid equivalents per

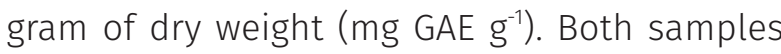
were analysed in quintuplicate.

\section{Total Flavonoid Content}

Total Flavonoids Content (TFC) was measured according to the methodology described by Woisky \& Salatino (1998) with modifications by Nunes et al. (2016). 3,3',4',5,7-pentahyd roxyflavone (Sigma-Aldrich, St. Louis, MO, USA) standard solutions (5.0, 10.0, 20.0, 30.0 and $40.0 \mu g \mathrm{~mL}^{-1}$ ) were prepared in $\mathrm{CH}_{3} \mathrm{OH}$ and used to construct a calibration curve. Total flavonoid content was expressed as quercetin equivalents per gram of dry extract ( $m g$ QE g ${ }^{-1}$ ). Both samples were analysed in quintuplicate.

\section{Total Condensed Tannins}

Total Tannin Content (TTC), proanthocyanidins, were determined according to the methodology described by Godefroot et al. (1981) and Morais et al. (2009) with modifications by Nunes et al. (2016). (2R,3S)-2-(3,4-dihydroxyphenyl)-3,4dihydro-2H-chromene-3,5,7-triol (Sigma-Aldrich, St. Louis, MO, USA) standard solutions (5.0, 10.0, $15.0,20.0,25.0$, and $30.0 \mu \mathrm{g} \mathrm{mL}$ ) were prepared in $\mathrm{CH}_{3} \mathrm{OH}$ and used to construct a calibration curve. The proanthocyanidins content was expressed as milligrams of catechin equivalents per gram of dry weight ( $\mathrm{mg} \mathrm{CE} \mathrm{g}{ }^{-1}$ ). Both samples were analysed in quintuplicate.

\section{DPPH Radical-Scavenging Activity}

The samples EEF and EEL extracts and the subfractions D3.5, D3.7, EA7.3, EA7.6, EA7.11.1, and EA7.11.4 were solubilized in $\mathrm{CH}_{3} \mathrm{OH}\left(1 \mathrm{mg} \mathrm{mL}^{-1}\right)$ and diluted to different concentrations ranging from 500 to $7.81 \mu \mathrm{g} \mathrm{mL}^{-1}$, and the assays were conducted by adding $2800 \mu \mathrm{L}$ of methanolic solution of DPPH (Sigma-Aldrich, St. Louis, MO, USA) (100 M) to $200 \mu \mathrm{L}$ of sample. The mixture was incubated for 40 min in the dark, and the absorbance of unreacted DPPH was used as the control. DPPH (2,2-diphenyl-1-picrylhydrazyl) scavenging activity was determined spectrophotometrically at $517 \mathrm{~nm}$. 3,4,5-trihydroxybenzoic acid was used as the standard, and the percent DPPH scavenging effect was calculated by using the following equation:

\% DPPH scavenging $=\left[\left(\right.\right.$ Abs $_{517 n m}$ (control) - Abs ${ }_{517 n m}($ sample $\left.)\right) /$ Abs $_{517 n m}($ control $\left.)\right] \times 100$

The $I C_{50}$ value, which is the concentration of sample required to inhibit $50 \%$ of the DPPH free radical, was calculated from the regression equation for the concentration of sample and percentage inhibition. The data were evaluated statistically using Minitab 18.0 software. The Ryan-Joiner test was used for analysis of normality distribution; this was followed by oneway analysis of variance (ANOVA) and the Tukey test post hoc. The level of statistical significance was defined as $p=0.05$. 


\section{Data Processing for Chemometrics Analysis}

All calculations were run using $\mathrm{R}$ software version 3.6.3 (TEAM 2020). MS data was analysed using R packages Msnbase version 2.12.0 (GATTO \& LILLEY 2012) and MALDIquant version 1.19.3 (GIBB \& STRIMMER 2012). Pre-treatment (peak alignment by the correlation optimized warping technique) and pre-processing (profile data) of the data matrices were applied. Peak data was binned using 0.0015 Da (5 ppm) bins and the resulting data matrix was Pareto scaled (peak intensities) using the R package MetabolAnalyze (GIFT et al. 2010). Hierarchical clustering analyses (HCA) and Principal component analyses (PCA) were run on the MS data to discriminate the metabolite contents in each extract. HCA was run using square Euclidean distance and Ward's method to link the clusters.

\section{Classical Molecular Networking Workflow Description}

A molecular network was created using the online workflow on the GNPS website (http:// gnps.ucsd.edu). Initially mass data obtained in .RAW format were converted to .mzXML files using the Msconvert, version 3.0, from ProteoWizard software (ProteoWizard, Palo Alto, CA, USA). The MS/MS spectra were window filtered by choosing only the top 6 fragment ions in the +/- 50 Da window throughout the spectrum. The precursor ion mass tolerance was set to $0.02 \mathrm{Da}$ and a MS/MS fragment ion tolerance of 0.02 Da. All matches kept between network spectra and library spectra were required to have a score above 0.6 and at least 6 matched peaks (Wang et al. 2016).

In the analysis, network annotation propagation (NAP) was utilized where the cosine value is to sub select inside a cluster of 0.65 , $\mathrm{N}$ first candidates for consensus score of 10 , accuracy for exact mass candidate search (ppm) of 15 , acquisition mode was negative, adduct ion type was $[\mathrm{M}-\mathrm{H}]$, and structure databases were GNPS and SUPNAT (da Silva et al. 2018). The nonannotated nodes in the classical analysis were submitted to NAP and later manually checked using patterns and mass data from the MoNa library (www.mona.fiehnlab.ucdavis.edu) in the respective fragmentation energy.

\section{RESULTS}

\section{Total Phenolic, Flavonoid and Tannin Contents}

The measured values of TPC, TFC, and TTC to EEL and EEF of B. laevifolia are presented in Table I. The ANOVA test identified statistical differences ( $p=0.05$ ) in phenolic content between the extracts of B. laevifolia, which observed larger quantities of phenolic compounds, flavonoids, and tannins for EEF.

\section{DPPH Radical-Scavenging Activity}

The Ryan-Joiner test showed that the data have a normal distribution, which described the continuous behaviour of the data, and therefore parametric tests were used to assess the equality of the $I C_{50}$ means of the samples. The ANOVA test showed different levels ( $p=$ 0.05) for radical scavenging capacity, which varied between $\mathrm{IC}_{50}$ values of $24.38 \pm 0.07 \mu \mathrm{g} \mathrm{mL} \mathrm{L}^{-1}$ and $679.18 \pm 0.06 \mu \mathrm{g} \mathrm{mL}^{-1}$ (Table II). The ANOVA analysis was supplemented by the Tukey test which allows for the evaluation and comparison between different $I C_{50}$ means as well as showing the similarity between the antioxidant capacity of EEF $\left(24.38 \pm 0.07 \mu \mathrm{g} \mathrm{mL} \mathrm{L}^{-1}\right)$ and the 3,4,5-trihydroxybenzoic acid standard (21.28 \pm $0.03 \mu \mathrm{g} \mathrm{mL} \mathrm{L}^{-1}$ ).

\section{Dereplication of phenolic compounds of $\boldsymbol{B}$. laevifolia by GNPS}

The GNPS molecular networking and NAP analysis allowed annotation of ten phenolic compounds (Figure 1), organized in the molecular 
Table I. Total phenolic content (expressed in mean \pm SD mg 3,4,5-trihydroxybenzoic acid equivalent/g dry weight), flavonoids content (expressed in mean \pm SD mg 3,3,4',5,7-pentahydroxyflavone equivalent/g dry weight), and tannins content (expressed in mean \pm SD mg 2-(3,4-dihydroxyphenyl)-3,4-dihydro-2H-1-benzopyran-3,5,7-triol equivalent/g dry weight) in Banisteriopsis laevifolia extracts.

\begin{tabular}{|c|c|c|}
\hline Total Content & $\begin{array}{c}\text { Ethanolic Extract of Flowers } \\
\text { (EEF) }\end{array}$ & $\begin{array}{c}\text { Ethanolic Extract of Leaves } \\
\text { (EEL) }\end{array}$ \\
\hline Phenolic compounds & $288.67 \pm 0.04 \mathrm{a}$ & $225.67 \pm 0.07 \mathrm{~b}$ \\
\hline Flavonoids & $199.87 \pm 0.13 \mathrm{c}$ & $173.30 \pm 0.08 \mathrm{~d}$ \\
\hline Tannins & $90.13 \pm 0.17 \mathrm{e}$ & $30.61 \pm 0.22 f$ \\
\hline
\end{tabular}

Values (means of five replicates) followed by different letters are significantly different at $p=0.05$.

Table II. Scavenging activity (mean \pm SD), expressed as inhibitory concentration ( $\mu \mathrm{g} \mathrm{mL}-1)$, in the DPPH test with extracts and sub-fractions of Banisteriopsis laevifolia.

\begin{tabular}{|c|c|}
\hline Sample & $\mathrm{DPPH}\left(\mathrm{IC}_{50}\right)$ \\
\hline 3,4,5-trihydroxybenzoic acid & $21.28 \pm 0.03 a$ \\
\hline EEF & $24.38 \pm 0.07 a$ \\
\hline EEL & $107.21 \pm 0.09 b$ \\
\hline D3.5 & $120.57 \pm 0.12 b c$ \\
\hline D3.7 & $154.52 \pm 0.24 C$ \\
\hline EA7.3 & $>1000 d$ \\
\hline EA7.6 & $573.08 \pm 0.13 \mathrm{ef}$ \\
\hline EA7.11.1 & $679.18 \pm 0.06 e$ \\
\hline EA7.11.4 & $401.42 \pm 0.02 f$ \\
\hline
\end{tabular}

Values (means of five replicates) followed by different letters are significantly different at $p=0.05$. EEF: ethanolic extract of flowers; EEL: ethanolic extract of leaves; D3.5, D3.7, EA7.3, EA7.6, EA7.11.1, and EA7.11.4: sub-fractions.

network in six main spectral families (Figure 2). In other words, family (2a) was formed by derivatives of 3',4',5,7-tetrahydroxyflavone $(\mathrm{m} / \mathrm{z}$ 285.041) (1), 3',4',5',5,7-pentahydroxyflavanone (m/z 301.036) (2), 4',5,7-trihydroxyflavanone (m/z 271.062) (3), and 3,4,5-trihydroxybenzoic acid ( $\mathrm{m} / \mathrm{z}$ 169.014) (4); family (2b) by derivatives of 2-(3,4-dihydroxyphenyl)-3,5,7-trihydroxy4H-chromen-4-one ( $\mathrm{m} / \mathrm{z}$ 301.036) (5); family (2c) by derivatives of $3-\{[6-0-(6-$ deoxy- $\alpha$ L-mannopyranosyl)- $\beta$-D-glucopyranosyl ] oxy]\}-2-(3,4-dihydroxyphenyl)-5,7-dihydroxy4H-1-Benzopyran-4-one ( $\mathrm{m} / \mathrm{z}$ 609.147) (6) and 2-(3,4-dihydroxyphenyl)-3-( $\beta$-Dglucopyranosyloxy)-5,7-dihydroxy-4H-1- benzopyran-4-one ( $m / z$ 463.095) (7); family (2d) by derivatives of 2,5-dihydroxybenzoic acid ( $m / z$ 153.019) (8); family (2e) by derivatives of 2-(3,4-dihydroxyphenyl)-3,4-dihydro-2H-1benzopyran-3,5,7-triol ( $\mathrm{m} / \mathrm{z}$ 289.073) (9); and family (2f) by derivatives of 3,4-dihydroxybenzoic acid ( $m / z$ 153.019) (10). The annotated compounds in B. laevifolia were confirmed to results in level 2 (MS/MS match and accurate mass - Sumner et al. 2007) and are shown in table III. Further information about MS/MS spectrum are provided in supplementary material (Figures S1 - S9). 
<smiles>[R9]c1cc(-c2cc(=O)c3c(O)cc(O)cc3o2)cc([13CH])c1[R8]</smiles><smiles>[R9]c1c([R9])c([2H])c(C(=O)O)c([R9])c1[2H]</smiles>

(4) $\mathrm{R}_{2}=\mathrm{R}_{6}=\mathrm{H} ; \mathrm{R}_{3}=\mathrm{R}_{4}=\mathrm{R}_{5}=\mathrm{OH}$ (8) $\mathrm{R}_{3}=\mathrm{R}_{4}=\mathrm{R}_{6}=\mathrm{H} ; \mathrm{R}_{2}=\mathrm{R}_{5}=\mathrm{OH}$ (10) $\mathrm{R}_{2}=\mathrm{R}_{5}=\mathrm{R}_{6}=\mathrm{H} ; \mathrm{R}_{3}=\mathrm{R}_{4}=\mathrm{OH}$<smiles>O=C1CC(c2ccc(O)cc2)Oc2cc(O)cc(O)c21</smiles><smiles>O=C1c2c(O)cc(O)cc2OC(c2ccc(O)c(O)c2)C1O</smiles><smiles>CC=C(C)c1oc2cc(O)cc(O)c2c(=O)c1Br</smiles>
(6) $\mathrm{R}_{1}=$ rutinoside; $\mathrm{R}_{2}=\mathrm{H} ; \mathrm{R}_{3}=\mathrm{R}_{4}=\mathrm{OH}$ (7) $\mathrm{R}_{1}=\mathrm{R}_{4}=\mathrm{OH} ; \mathrm{R}_{2}=\mathrm{H} ; \mathrm{R}_{3}=\mathrm{O}$-glucoside

Figure 1. Structures of phenolic compounds identified by GNPS and NAP.
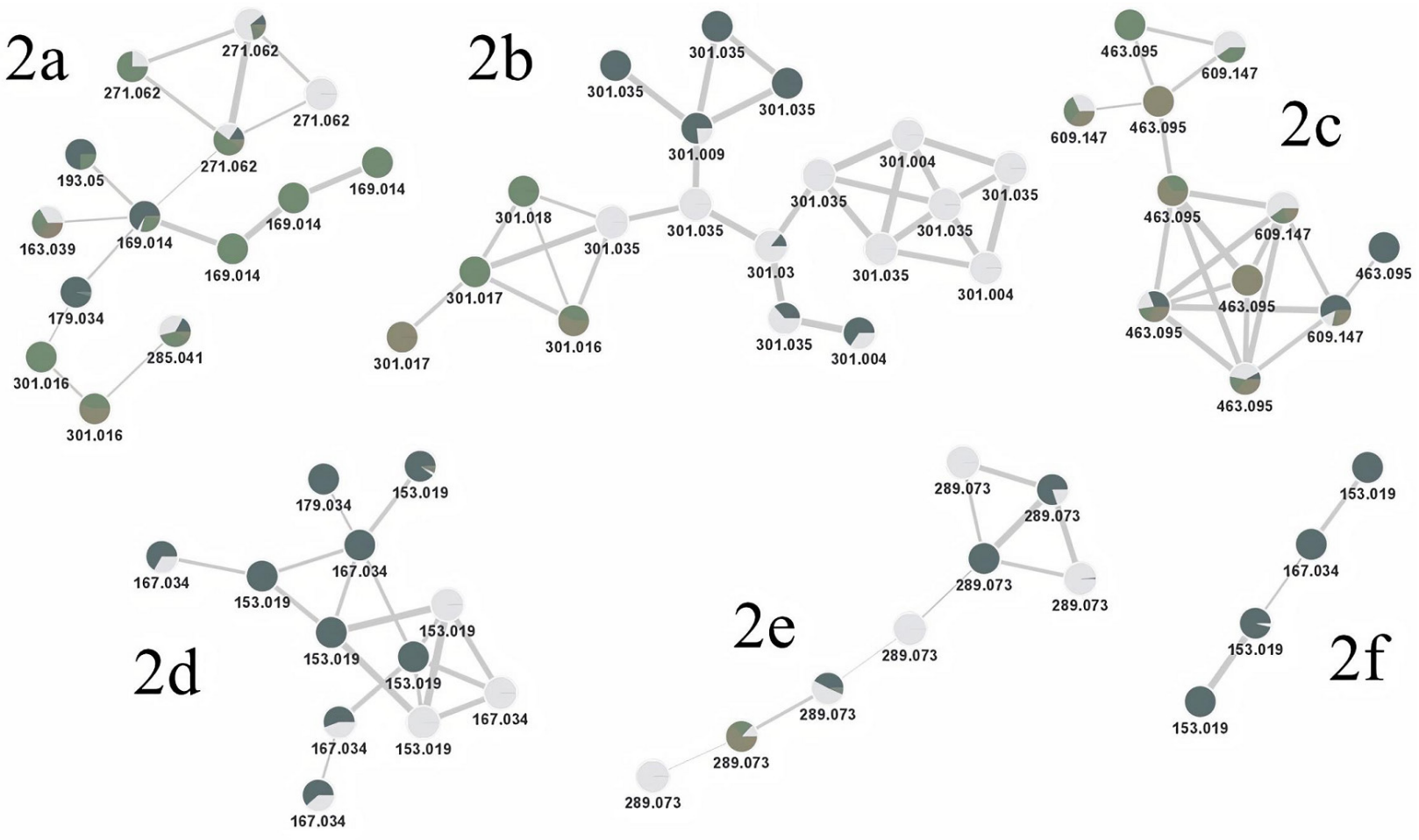

Figure 2. Full classical molecular network realized using MS/MS data and visualized in Cytoscape from the ethanolic extracts of flowers (EEF), leaves (EEL), and sub-fractions obtained from EEF of B. laevifolia. 


\begin{tabular}{|c|c|c|c|c|c|c|c|c|c|c|}
\hline $\begin{array}{l}\frac{0}{0} \\
\frac{0}{\bar{E}} \\
\text { 心 }\end{array}$ & 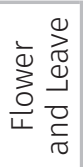 & 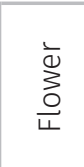 & 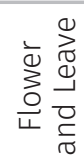 & 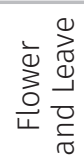 & 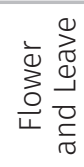 & 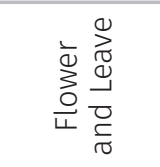 & 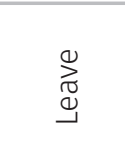 & 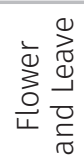 & 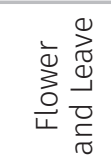 & 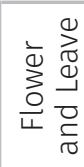 \\
\hline 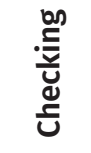 & $\begin{array}{l}\frac{0}{0} \\
\frac{0}{0} \\
\frac{0}{0} \\
\dot{n} \\
\text { in }\end{array}$ & 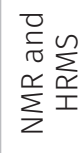 & $\begin{array}{l}\frac{D}{\frac{0}{\pi}} \\
\frac{\pi}{0} \\
\frac{D}{0} \\
\stackrel{D}{n}\end{array}$ & 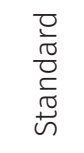 & 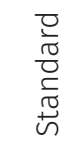 & $\begin{array}{l}\frac{0}{0} \\
\frac{0}{0} \\
\frac{0}{0} \\
\frac{\pi}{4} \\
\text { in }\end{array}$ & $\begin{array}{l}\frac{0}{0} \\
0 \\
0 \\
0 \\
0 \\
i n\end{array}$ & 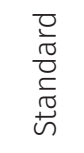 & 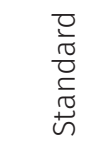 & $\begin{array}{l}\frac{\pi}{2} \\
\sum \\
\sum\end{array}$ \\
\hline 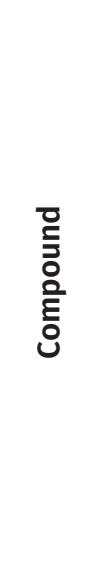 & 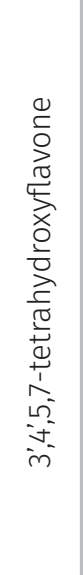 & 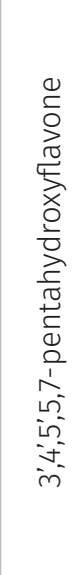 & 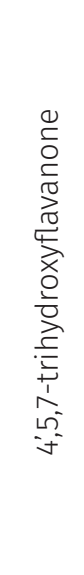 & 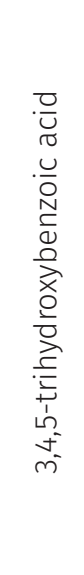 & 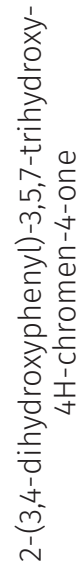 & 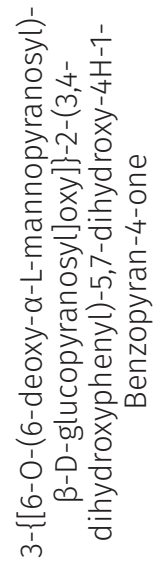 & 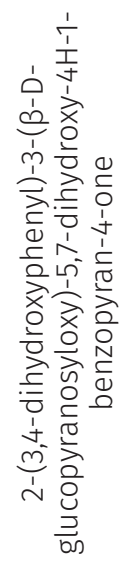 & 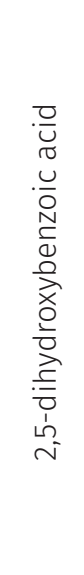 & 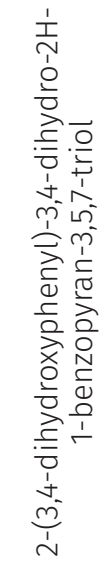 & 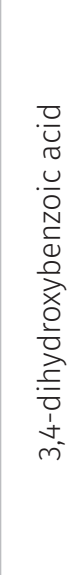 \\
\hline$\tilde{N}_{\Sigma}^{N}$ & 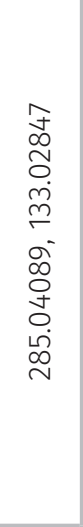 & 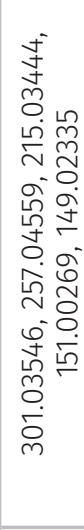 & 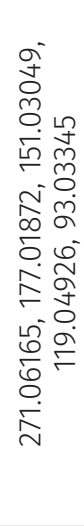 & 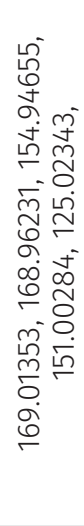 & 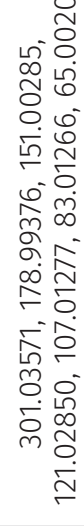 & 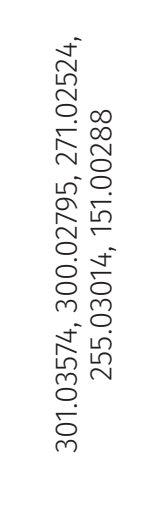 & 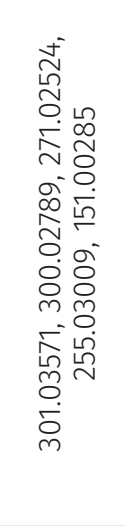 & 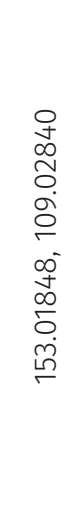 & 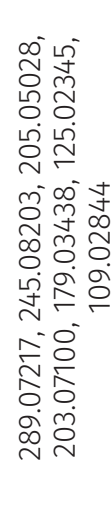 & 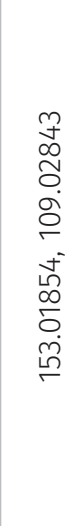 \\
\hline 온 & $\underset{\text { F }}{\stackrel{F}{m}}$ & $\begin{array}{l}\stackrel{8}{\circ} \\
\dot{m}\end{array}$ & $\stackrel{i}{i}$ & $\underset{\Gamma}{\sigma}$ & $\stackrel{\text { }}{\sim}$ & $\underset{\sim}{\tilde{J}}$ & I & హे & 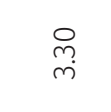 & $\stackrel{\leftrightarrow}{\stackrel{\leftrightarrow}{2}}$ \\
\hline$\frac{1}{\sum^{\frac{1}{\Sigma}}}$ & $\begin{array}{l}\text { o } \\
0 \\
\text { वे } \\
0 \\
\text { Lे } \\
\stackrel{\infty}{\sim}\end{array}$ & 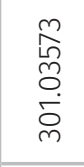 & 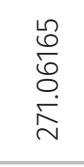 & 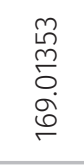 & $\begin{array}{l}\sqrt{\tilde{N}} \\
\tilde{\gamma} \\
\dot{\sigma} \\
\bar{m}\end{array}$ & 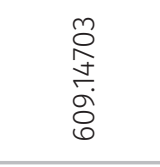 & 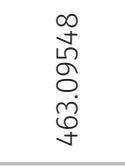 & 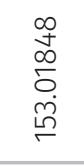 & 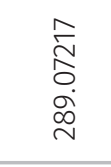 & 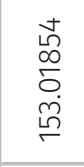 \\
\hline 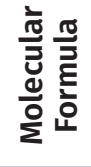 & $\begin{array}{l}0_{0}^{0} \\
I^{0} \\
U^{n}\end{array}$ & $\begin{array}{l}0_{0}^{-} \\
I^{-} \\
v^{n}\end{array}$ & $\begin{array}{l}0_{\Omega}^{n} \\
I^{n} \\
U_{n}^{n}\end{array}$ & $\begin{array}{l}O_{0}^{n} \\
I^{0} \\
u^{\prime}\end{array}$ & $\begin{array}{l}0_{0}^{\prime} \\
I^{-} \\
u^{n}\end{array}$ & $\begin{array}{l}0_{0}^{o} \\
I^{m} \\
U^{\tilde{m}}\end{array}$ & $\begin{array}{l}0^{2} \\
I^{2} \\
u^{v}\end{array}$ & $\begin{array}{l}O_{0}^{+} \\
I^{\prime} \\
v^{\prime}\end{array}$ & 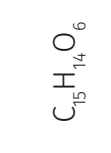 & $\begin{array}{l}O_{0}^{+} \\
I^{+} \\
u^{\prime}\end{array}$ \\
\hline$\stackrel{\widehat{E}}{\underline{\underline{E}}}$ & $\underset{\infty}{\sim}$ & $\underset{\sim}{\stackrel{ }{\sim}}$ & $\begin{array}{l}\stackrel{m}{\infty} \\
\stackrel{\infty}{\sim}\end{array}$ & $\stackrel{\bar{m}}{\sim}$ & $\begin{array}{l}\stackrel{\infty}{o} \\
\stackrel{\sim}{\sim}\end{array}$ & 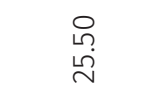 & $\begin{array}{l}\ddot{\Theta} \\
\stackrel{\sim}{\sim}\end{array}$ & $\stackrel{m}{\stackrel{n}{\sigma}}$ & $\stackrel{\circ}{\stackrel{ }{i}}$ & $\underset{\stackrel{f}{ \pm}}{\stackrel{\sim}{\sim}}$ \\
\hline$\#$ & - & $\sim$ & $m$ & t & $\llcorner\cap$ & 0 & $\wedge$ & $\infty$ & $a$ & 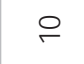 \\
\hline
\end{tabular}




\section{Isolated Compounds}

A mixture of flavonoids (1) and (2) and the diterpenoid 18-hydroxy-ent-halima-1(10),13-(E)dien-15-oic acid (11) were isolated and identified by NMR (1D \& 2D) spectra and HRMS. The analysis in negative mode very clearly shows the ion peak at $285.04047[\mathrm{M}-\mathrm{H}]^{-}$(error $3.8 \mathrm{ppm}$ ) indicating the molecular formula $\mathrm{C}_{15} \mathrm{H}_{9} \mathrm{O}_{6}$ which suggested the identification of flavonoid (1); flavonoid (2) was identified according to the another set of ${ }^{1} \mathrm{H}$ NMR aromatic hydrogen signals, by comparison from the literature, and the ion $[\mathrm{M}-\mathrm{H}]^{-} 301.03573$ (error $3.6 \mathrm{ppm}$ ), indicating the molecular formula $\mathrm{C}_{15} \mathrm{H}_{9} \mathrm{O}_{7}$ (Guzel 2020).

Compound (11) was identified by the ${ }^{1} \mathrm{H}$ NMR spectrum from the diagnostic olefinic hydrogen at $\delta 5.35$ (sl), two tertiary methyl groups at $\delta 0.96$ (s) and $\delta 0.94(s)$, and one secondary methyl group at $\delta 0.84(d, 7.5 \mathrm{~Hz})$, suggesting a typical halimane type diterpenoid, with presence of hydroxy methylene group at $\delta 3.34(d, 10 \mathrm{~Hz}$, $1 \mathrm{H})$ and $\delta 3.50(\mathrm{~d}, 10 \mathrm{~Hz}, 1 \mathrm{H})$ was attributed to C4 as in an ent-halimane diterpene found and isolated by Monteiro et al. (2015). The HMBC analysis showed the $\alpha, \beta$ unsaturated carboxy group side chain (Supplementary Material Table SI). The MS analysis in the negative mode presents molecular ion peaks $\mathrm{m} / \mathrm{z} 319.22742$ $[\mathrm{M}-\mathrm{H}]^{-}$and positive mode $\mathrm{m} / \mathrm{z} 321.24228[\mathrm{M}+\mathrm{H}]^{+}$ which suggested the molecular formula $\mathrm{C}_{20} \mathrm{H}_{32} \mathrm{O}_{3}$ (error negative mode $=0.6 \mathrm{ppm}$ and positive mode $=2.1 \mathrm{ppm}$ ).

\section{DISCUSSION}

The Malpighiaceae family and species of the genus Banisteriopsis have a large number of phenolic compounds (Frias et al. 2012). These compounds form a versatile class of secondary metabolites widely present in higher plants. They are varied in terms of structures and are classified according to the number of aromatic rings and the structure that connects the rings (Heleno et al. 2015, Dias et al. 2015, Khan et al. 2020). Flavonoids and tannins are important groups of polyphenols that show important functions in vegetables, and the content of these metabolites in a plant results from a sum of physiological and environmental factors (Jin 2019, Khan et al. 2020).

Our results (Table I) have demonstrated a higher content of phenolic compounds, flavonoids, and tannins in the flowers (EEF) of B. laevifolia. A comparison of the minimum statistically significant difference, Tukey test, between EEF and EEL measured contents confirmed the preferential accumulation of these compounds in flower tissues. According to Medini et al. (2014), this accumulation process may occur during the plant development stage. Phenolic compounds might be found in all parts of a plant during the flowering stage; however, they are preferentially accumulated in the epidermal tissues of flowers and contribute to the mechanisms of defence and attraction of pollinating agents (Pietta 2000, Medini et al. 2014, Jiang et al. 2016).

The phenolic compounds represent an important class of metabolites to combat and prevent oxidative stress caused by free radicals, and inactivation mechanisms occur through reduction reactions, by means of electron transfer, which yield stable molecules (Alves et al. 2010, Braham et al. 2020, Khan et al. 2020). The evaluation of potential sequestration of the DPPH radical for $B$. laevifolia samples was performed, followed by analysis of variance and the Tukey test for all possible pairs of $I C_{50}$ for $B$. laevifolia present in Table II. The results pointed out a statistical similarity between the standard (3,4,5-trihydroxybenzoic acid standard) and the EEF sample, demonstrating the high antioxidant activity of the sample. The antioxidant capacity 

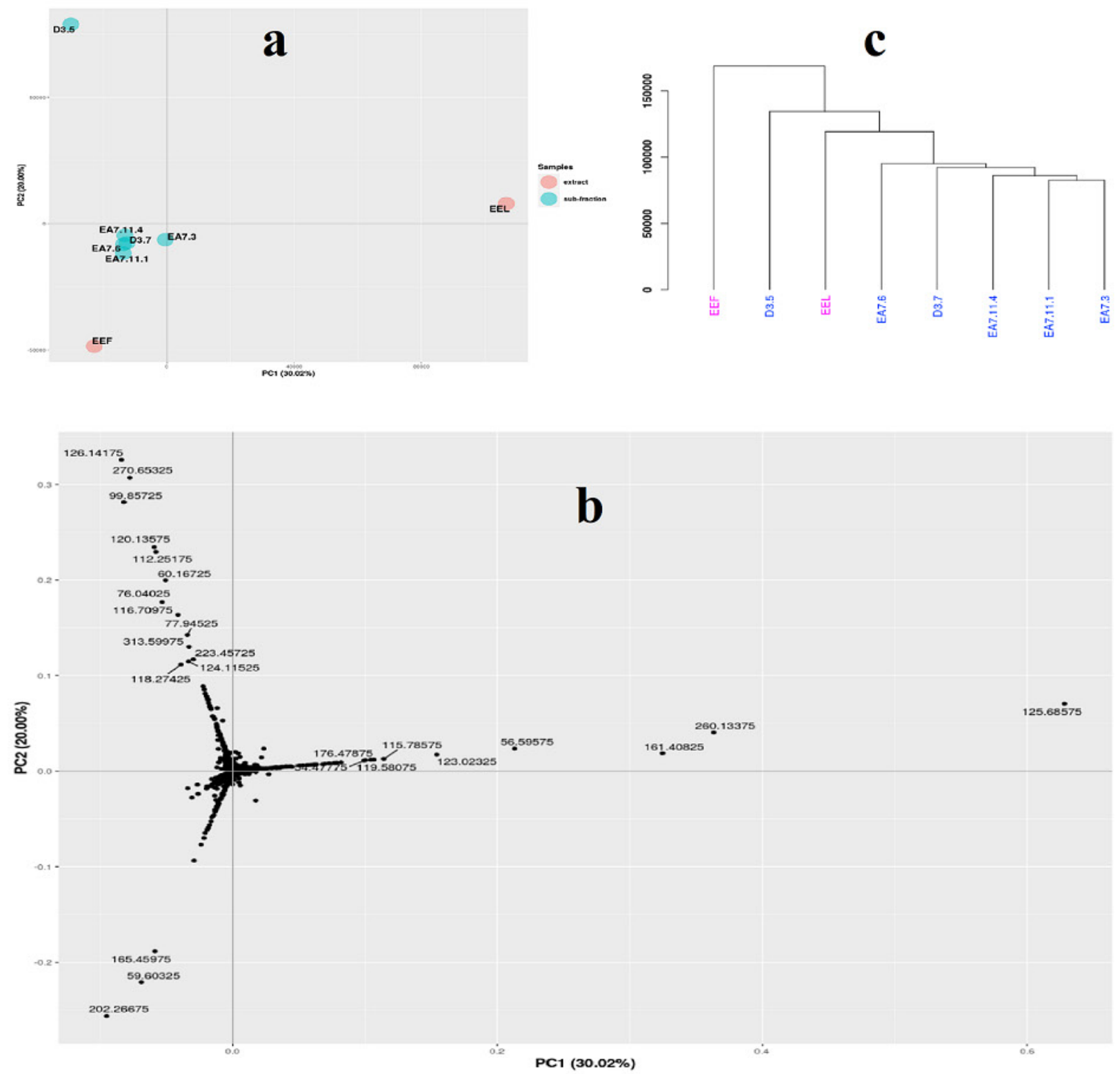

Figure 3. Principal component plots and a dendrogram of MS data: a) score plot for PC1 x PC2; b) loadings for PC1 x PC2; c) HCA dendrogram. Ethanolic extracts: EEL (leaves), EEF (flowers); Sub-fractions: D3.5, D3.7, EA7.6, EA7.11.1, EA7.11.4, and EA7.3.

for the other samples were classified, according to Mensor et al. (2001), as moderate (EEL, D3.5, and D3.7) and weak (EA7.3, EA7.6, EA7.11.1, and EA7.11.4).

PCA was then applied to identify chemical similarities on the MS data that might be related to the observed antioxidant activity. The first two principal components (PC1 and PC2) explained $50 \%$ of the total MS data variance and according to the score plot in Figure 3a; PC1 discriminates
EEL (right side) from the rest of the samples. According to the plot of the loadings for PC1, Figure $3 b$, the $\mathrm{m} / \mathrm{z}$ peaks having the highest loading values (>0.2) are 56.596, 161.408, 260.134, and 125.686, and these are the most important ions responsible for distancing EEL. The ion $\mathrm{m} / \mathrm{z} 125.686$ (the farthest point on the right in Figure $3 b$ ) comes from the fragmentation of 3,4,5-trihydroxybenzoic acid. This compound is 
the most abundant phenolic acid in B. laevifolia metabolism, and it has been demonstrated to be an important antioxidant component responsible for the efficient radical scavenging (Badhani et al. 2015).

All sub-fractions but D3.5 are grouped together at the centre of Figure 3a. The subfraction D3.5 (top left) presents a different pattern, mainly because of the high positive loading values from $\mathrm{m} / \mathrm{z}$ peaks 99.857, 270.653, and 126.142 (Figure 3b). The sample EEF (bottom left) is also discriminated from the rest of the samples owing to the $\mathrm{m} / \mathrm{z}$ peaks $165.460,59.603$, and 202.267.

The dendrogram in Figure $3 c$ presents the clustering beginning from sub-fractions (at the left) and follows until the extracts (at the right), except for the sample D3.5. The grouping in Figure $3 \mathrm{c}$ is very similar to the pattern found from the PCA results. Although the four compounds identified in sub-fraction D3.5 are not as many as the eight compounds identified in EEF, it is possible that the antioxidant elevation of this sub-fraction is associated with the presence of 3,4,5-trihydroxybenzoic acid, confirmed by a reference standard, as well as the synergistic effect of the fewer compounds (Heim et al. 2002).

According to Figure $3 \mathrm{a}$, there are four groups: 1) $E E L$; 2) $E E F$; 3) D3.5, and 4) remaining subfractions. A new PCA (supplementary material, Figure S10) was applied to the group 4 samples and characteristic ions identified. However, since these ions presented small $\mathrm{m} / \mathrm{z}$ values, they could not be related to any specific chemical compound in database libraries.

Through PCA analysis, the similarity in chemical composition between extracts and fractions of $B$. laevifolia can be observed through the common molecular fragments present in the samples. Thus, in order to elucidate the families of compounds among the extracts and fractions, GNPS dereplication was employed.
After processing the MS/MS data on the GNPS platform, the molecular networks obtained were processed and analyzed using Cytoscape software, version 3.8.2, followed by NAP analysis in order to note the possible corresponding structures of phenolic compounds present in B. laevifolia (Sumner et al. 2007, Mannochio-Russo et al. 2020). The families were formed by nodes with the same mass fragmentation profiles. In family $2 \mathrm{a}$, derived structure of (1) with molecular

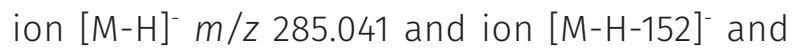
derived of (2) molecular ion $[\mathrm{M}-\mathrm{H}]^{-} \mathrm{m} / \mathrm{z} 301.036$ were observed from EEF in sub-fractions D3.7 and EA7.6. Also, in this family, derived of (3) were annotated from EEL and EEF in sub-fractions D3.5, D3.7, and EA7.6 with the quasi-molecular ion $[\mathrm{M}-\mathrm{H}]^{-} \mathrm{m} / \mathrm{z} 271.062$ and ions [M-H-94]', [M-H120], and [M-H-152]. From compound (3), it was possible to search compound (4) from EEL and EEF in sub-fractions D3.5, D3.7, and EA7.6 with quasi-molecular ion [M-H], m/z 169.014 and ions [M-H-18] (annotated through NAP) and [M$\mathrm{H}-44]^{-}$(Boudiar et al. 2019).

In family $2 b$, all nodes have the same mass as the precursor ion. Thus, compound (5) was identified in EEL and EEF with the quasimolecular ion $[\mathrm{M}-\mathrm{H}]^{-} \mathrm{m} / \mathrm{z} 301.036$ and other fragment ions with $\mathrm{m} / \mathrm{z}$ 178.994, 151.003, 121.028, 107.013, 83.013, and 65.002 (Oliveira et al. 2018).

The family $2 c$ presents nodes with differences of $\mathrm{m} / \mathrm{z}$-146.052. In this family, derived of (6), with quasi-molecular ion $[\mathrm{M}-\mathrm{H}]^{-} \mathrm{m} / \mathrm{z} 609.147$ and ions $\mathrm{m} / \mathrm{z} 301.036$ and $\mathrm{m} / \mathrm{z} 300.028$, was annotated from EEL and EEF in sub-fractions D3.5 and EA7.6 (Boudiar et al. 2019, Cuyckens \& Claeys 2004). It is evident that the neighbouring node is derived from the loss of a rhamnosyl fragment (Okonkwo et al. 2016). This suggests the presence of derived of (7) from EEL and EEF in sub-fractions D3.5, D3.7, EA7.3, and EA7.6, with ions $\mathrm{m} / \mathrm{z}$ 301.036, 300.028, 271.025, 255.030, and 151.003 (Cifuentes et al. 2020). 
In the family $2 \mathrm{~d}$ and $2 \mathrm{f}$, the clusters formed by ions from EEF and EEL samples, showed the presence of compounds (8) and (10). The quasi-molecular ion m/z [M-H] 153.019 availed compound (8), while the base peak ion [M-H-44] $^{-} \mathrm{m} / \mathrm{z} 109.028$ (Zhang et al. 2018) suggested compound (10). The existence and fragmentation pattern of compound (10) agrees with the data reported in the literature (Bhagya \& Chandrashekar 2020, Mallmann et al. 2020). However, precise information on retention time would be necessary, as these dihydroxy acids have at least six isomers that present the $\mathrm{m} / \mathrm{z}$ $[\mathrm{M}-\mathrm{H}]^{-}$and $\left[\mathrm{M}-\mathrm{CO}_{2}\right]^{-}$(Belaya 2020). The family $2 \mathrm{e}$ presents a node identified as compound (9), which was obtained from EEL and EEF, with a quasi-molecular ion [M-H] $^{-} \mathrm{m} / \mathrm{z} 289.073$ and ions $245.082,205.050,203.071,179.034,125.023$, and 109.028 .

Compounds (5) and (9) fragmentation profiles were also identified and reported for B. argyrophylla (Oliveira et al. 2018). In addition, compounds (6) and (9) were also reported in B. laevifolia species (Nunes et al. 2016). To the best of our knowledge, this is the first time that compounds (1-4), (7), (8) and (10) are reported in $B$. laevifolia. This finding may contribute to an understanding of the antioxidant activity of the leaves and flower extracts of B. laevifolia, and the identification of these nine phenolic compounds brings added importance from the chemical, biological, and species preservation point of view and to the benefits that these phenolic compounds can bring to human health (Durazzo et al. 2019, Imran et al. 2019).

In spite of the inadequate studies and scarce information in the literature about the $B$. laevifolia species, this work on dereplication by HPLC-ESI-MS and antioxidant activity of phenolic compounds from B. laevifolia (Malpighiaceae) contributes to knowledge about the genus Banisteriopsis in general and opens avenues for continuing research on the $B$. laevifolia species in particular. From the findings reported herein, it is possible to understand the differences in the antioxidant activities between extracts and subfractions through data processing with PCA. The antioxidant activity is related to the chemical composition of the extracts or sub-fractions with particular reference to the $\mathrm{HO}^{-}$groups as well as to the substitution pattern on the flavonoid structures (Heim et al. 2002). Phenolic compounds that have two $\mathrm{HO}^{-}$substitutions in ring $\mathrm{B}$ exhibited greater antioxidant activity than those with an $\mathrm{HO}^{-}$substitution. Hence, compound (5) and its derivatives have greater antioxidant activity than 3,5,7-trihydroxy-2-(4hydroxyphenyl)chromen-4-one (Cao et al. 1997). It is supposed that the activity recorded for the isolates and extracts of B. laevifolia in this study was to a large extent influenced by this fact.

Although ent-halimane diterpene (11) was previously isolated from Hymenaea stigonocarpa (Monteiro et al. 2015), this study pioneered its presence for the first time in B. laevifolia species. Further phytochemical studies with other species of Banisteriopsis are needed to fully understand the chemosystematic significance of these compounds in this genus. The high diversity of metabolites found in this study and those which have reported for the Banisteriopsis genus strongly recommend further investigation into the chemical and biological properties of its species.

\section{Acknowledgments}

We are grateful to the Dr. Aristônio Magalhães Teles for the authentication of the vegetal material. We are also thankful to the Conselho Nacional de Desenvolvimento Científico e Tecnológico (CNPq) for supporting this research (process no 422513/2016-4) and to the Regional Center for Technological Development and Innovation for performing the HPLC-MS analyses. A.E.O. also thanks CNPq for DT fellowship 315276/2018-5. 


\section{REFERENCES}

ALVES CQ, DAVID JM, DAVID JP, BAHIA MV \& AGUIAR RM. 2010. Methods for determination of in vitro antioxidant activity for extracts and organic compounds. Quim Nova 33: 2202-2210.

ANDERSON WR \& DAVIS CCA. 2010. Complete generic phylogeny of Malpighiaceae inferred from nucleotide sequence data and morphology. Am J Bot 97: 2031-2048.

BADHANI A, RAWAT S, BHATT ID \& RAWAL RS. 2015. Variation in chemical constituents and antioxidant activity in yellow Himalayan (Rubus ellipticus Smith) and hill Raspberry (Rubus niveus Thumb). J Food Biochem 39(6): 663-672.

BATALHA MO \& MING LC. 2004. Plantas medicinais e aromáticas: um estudo de competitividade no Estado de São Paulo. São Paulo: SEBRAE-SP, 240 p.

BELAYA NI. 2020. Factor analysis of the relationship of the chemical structure and anti-radical activity of natural phenols. Russ J Appl Chem 93: 149-158.

BHAGYA N \& CHANDRASHEKAR KR. 2020. Identification and quantification of cytotoxic phenolic acids and flavonoids in Ixora brachiata by UHPLC-DAD and UHPLC-ESI-MS/MS. Int J Mass Spectrom 450: 1-7.

BOUDIAR T, LOZANO-SÁNCHEZ J, HARFI B, CONTRERAS MM \& SEGURA-CARRETERO A. 2019. Phytochemical characterization of bioactive compounds composition of Rosmarinus eriocalyx by RP - HPLC-ESI-QTOF-MS. Nat Prod Res 33: 2208-2214.

BRAHAM F, CARAVALHO DO, ALMEIDA CMR, ZAIDI F, MAGALHÃES JMCS, GUIDO LF \& GONÇALVES MP. 2020. Online HPLC-DPPH screening method for evaluation of radical scavenging phenols extract from Moringa oleifera leaves. S Afr J Bot 129: 146-154.

CAO G, SOFIC E \& PRIOR RL. 1997. Antioxidant and prooxidant behavior of flavonoids: structure-activity relationships. Free Radical Bio Med 22: 749-760.

CHEN G, FAN M, WU J, LI N \& GUO M. 2019. Antioxidant and anti-inflammatory properties of flavonoids from lotus plumule. Food Chem 277: 706-712.

CIFUENTES F, PALACIOS J, BÓRQUEZ J, PAREDES A, PARRA C, BRAVO A \& SIMIRGIOTIS MJ. 2020. Fast isolation of flavonoids from the endemic species Nolana ramosissima I.M Johnst and its endothelium-independent relaxation effect in rat aorta. Molecules 25: 1-17.

CUYCKENS F \& CLAEYS M. 2004. Mass spectrometry in the structural analysis of flavonoids. J Mass Spectrom 39: $1-15$.
DA-SILVA RR ET AL. 2018. Propagating annotations of molecular networks using in silico fragmentation. Plos Comput Biol 14: 1-26.

DIAS MI, SOUSA MJ, ALVES RC \& FERREIRA ICFR. 2015. Exploring plant tissue culture to improve the production of phenolic compounds: a review. Ind Crop Prod 82: 9-22.

DURAZZO A, LUCARINI M, SOUTO EB, CICALA C, CAIAZZO E, IZZO AA, NOVELLINO E \& SANTINI A. 2019. Polyphenols: a concise overview on the chemistry, occurrence, and human health. Phytother Res 33: 2221-2243.

FREITAS LBO, BOAVENTURA MAD, SANTOS WL, STEHMANN JL, JUNIOR DD, LOPES MTP, MAGALHÃES TFF, DA SILVA DL \& RESENDE MA. 2015. Allelopathic, cytotoxic and antifungic activities of new dihydrophenanthrenes and other constituents of leaves and roots extracts of Banisteriopsis anisandra (Malpighiaceae). Phytochem Lett 12: 9-16.

FRIAS UA, COSTA MCM \& TAKAHASHI JA. 2011. Caracterização fitoquímica e avaliação das atividades antibacteriana e anticolinesterásica de extratos de Banisteriopsis anisandra A. Juss. (Malpighiaceae). Rev Cuba Plantas Med 16: 60-71.

FRIAS UA, COSTA MCM, TAKAHASHI JA \& OKI Y. 2012. Banisteriopsis Species: A source of bioactive of potential medical application. Int J of Biotech Well Indus 1: 163-171.

GATTO L \& LILLEY KS. 2012. MSnbase-an R/Bioconductor package for isobaric tagged mass spectrometry data visualization, processing and quantitation. Bioinformatics 28: 288-289.

GIBB S \& STRIMMER K. 2012. MALDI quant: a versatile R package for the analysis of mass spectrometry data. Bioinformatics 28: 2270-2271.

GODEFROOT M, SANDRA P \& VERZELE M. 1981. New method for quantitative essecial oil analyses. J Chromatogr A 203: 325-335.

GUARIM-NETO G \& MORAIS RG. 2003. Recursos medicinais de espécies do cerrado de Mato Grosso: um estudo bibliográfico. Acta Bot Bras 17: 561-584.

GUZEL Y. 2020. Specialized natural product analysis and chemophenetics of some Turkish endemic Centaurea L. (Asteraceae) taxa by electrospray ionization mass spectrometry fingerprinting and liquid chromatographytandem mass spectrometry. Biochem Syst Ecol 91: 104079.

HEIM KE, TAGLIAFERRO AR \& BOBILYA DJ. 2002. Flavonoid antioxidants: chemistry, metabolism and structureactivity relationships. J Nutr Biochem 13: 572-584. 
HELENO AS, MARTINS A, QUEIROZ MJRP \& FERREIRA ICRF. 2015. Bioactivity of phenolic acids: metabolites versus parent compounds: a review. Food Chem 173: 501-513.

IMRAN M ET AL. 2019. Luteolin, a flavonoid, as an anticancer agent: A review. Biomed Pharmacother 112: 1-10.

JIANG N, DOSEFF AI \& GROTEWOLD E. 2016. Flavones: from biosynthesis to health benefits. Plants-Basel 5: 1-25.

JIN YS. 2019. Recent advances in natural antifungal flavonoids and their derivates. Bioorg Med Chem Lett 29: 1-13.

KHAN M, LIU H, WANG J \& SUN B. 2020. Inhibitory effect of phenolic compounds and plant extract on the formation of advance glycation end products: a comprehensive review. Food Res Int 130: 1-14.

KLINK CA \& MACHADO RB. 2005. A Conservação do Cerrado Brasileiro. Megadiversidade 1: 147-155.

MALLMANN LP, TISCHER B, VIZZOTTO M, RODRIGUES E \& MANFROI V. 2020. Comprehensive identification and quantification of unexploited phenolic compounds from red and yellow araçá (Psidium cattleianum Sabine) by LC-DAD-ESI-MS/ MS. Food Res Int 131: 1-9.

MANNOCHIO-RUSSO H, BUENO PCP, BAUERMEISTERA, DE ALMEIDA RF, DORRESTEIN PC, CAVALHEIRO AJ \& BOLZANI VS. 2020. Can Statistical Evaluation Tools for Chromatographic Method Development Assist in the Natural Products Workflow? A Case Study on Selected Species of the Plant Family Malpighiaceae. J Nat Prod 83: 3239-3249.

MEDINI F, FELLAH H, KSOURI R \& ABDELLY C. 2014. Total phenolic, flavonoid and tannin contents and antioxidant and antimicrobial activities of organic extracts of shoots of the plant Limonium delicatulum. J Taibah Univ Sci 8: 216-224.

MENSOR LL, MENEZES FS, LEITÃO GG, REIA AS, SANTOS TC, COUBE CS \& LEITÃO SG. 2001. Screening of Brazilian plant extracts for antioxidant activity by the use of DPPH free radical method. Phytother Res 15: 127-130.

MONTEIRO AF ET AL. 2015. Structure and absolute configuration of diterpenoids from Hymenaea stigonocarpa. J Nat Prod 78:1451-1455.

MORAIS SAL, AQUINO FJT, NASCIMENTO PM, NASCIMENTO EA \& CHANG R. 2009. Bioactive compounds and antioxidant activity of conilon coffee submitted to different degrees of roasting. Quim Nova 32 (2): 327-331.

NUNES BC ET AL. 2016. Antimicrobial activity, cytotoxicity and selectivity index of Banisteriopsis laevifolia (A. Juss.) B. Gates leaves. Ind Crop Prod 92: 277-289.
OKONKWO CJ, NJOKU OU, OKONKWO TJN, AFIEROHO OE \& PROKSCH P. 2016. Two new acylated flavonol glycosides from Mimosa pigra L. leaves sub-family Mimosoideae. Future J Pharm Sci 2: 71-75.

OLIVEIRA DM ET AL. 2018. Antifungal and cytotoxicity activities of Banisteriopsis argyrophylla leaves. J Pharm Pharmacol 70: 1541-1552.

PÁDUA MS, MENDES-COSTA MC, FERREIRA JMS, MAGALHÃES JC \& CASTRO AHF. 2013. Assessment of antimicrobial activity in vitro of ethanolic extracts of Banisteriopsis anisandra (A. Juss.) B. Gates (Malpighiaceae). Rev Bras Pl Med 15: 431-437.

PIETTA PG. 2000. Flavonoids as antioxidants. J Nat Prod 63: 1035-1042.

RODRIGUES VEG \& CARVALHO DA. 2001. Ethnobotanical survey of medicinal plants in the dominion of meadows in the region of the Alto Rio Grande - Minas Gerais. Cienc Agrotec 25: 102-122.

SCHWARZ MJ, HOUGHTON PJ, ROSE S, JENNER P \& LEES AD. 2003. Activities of extract and constituents of Banisteriopsis caapi relevant to parkinsonism. Pharmacol Biochem Behav 75: 627-633.

SOUSA CMM ET AL. 2007. Total phenolics and antioxidant activity of five medicinal plants. Quim Nova 30, 351-355.

SUMNER LW ET AL. 2007. Proposed minimum reporting standards for chemical analysis. Metabolomics 3: 211-221.

TEAM RC. 2020. R: a language and environment for statistical computing. Vienna, Austria: URL https:// www.R-project.org].

WANG M ET AL. 2016. Sharing and community curation of mass spectrometry data with Global Natural Products Social Molecular Networking. Nat Biotechnol 34: 828-837.

WANG YH ET AL. 2010. Composition, standardization and chemical profiling of Banisteriopsis caapi, a plant for the treatment of neurodegenerative disorders relevant to Parkinson's disease. J Ethnopharmacol 128: 662-671.

WOISKY RG \& SALATINO A. 1998. Analysis of propolis: some parameters and procedures for chemical quality control. J Apic Res 37: 99-105.

ZHANG G, CHEN S, ZHOU W, MENG J, DENG K, ZHOU H, HU N \& SUO Y. 2018. Rapid qualitative and quantitative analyses of eighteen phenolic compounds from Lycium ruthenicum Murray by UPLC-Q-Orbitrap MS and their antioxidant activity. Food Chem 269: 150-156. 


\section{SUPPLEMENTARY MATERIAL}

Figure S1. MS/MS spectral pattern of 3,4',5,7-tetrahydroxyflavone.

Figure S2. MS/MS spectral pattern of 4,5,7-trihydroxyflavanone.

Figure S3. MS/MS spectral pattern of 3,4,5-trihydroxybenzoic acid.

Figure S4. MS/MS spectral pattern of 2-(3,4-dihydroxyphenyl)-3,5,7-trihydroxy-4H-chromen4-one.

Figure S5. MS/MS spectral pattern of 3-\{[6-0-(6-deoxy$\alpha$-L-mannopyranosyl)- $\beta$-D-glucopyranosyl]oxy]\}-2-(3,4dihydroxyphenyl)-5,7-dihydroxy-4H-1-benzopyran-4one.

Figure S6. MS/MS spectral pattern of 2-(3,4-dihydroxyphenyl)-3-( $\beta$-D-glucopyranosyloxy)5,7-dihydroxy-4H-1-benzopyran-4-one.

Figure S7. MS/MS spectral pattern of 2,5-dihydroxybenzoic acid.

Figure S8. MS/MS spectral pattern of 2-(3,4-dihydroxyphenyl)-3,4-dihydro-2H-1-benzopyran3,5,7-triol.

Figure S9. MS/MS spectral pattern of 3,4-dihydroxybenzoic acid.

Figure S10. Principal component plots for MS data of the sub-fractions D3.7, EA7.3, EA7.6, EA7.11.1, and EA7.11.3: a) score plot for PC1 x PC2; b) loadings for PC1 $x$ PC2.

Table SI. $1 \mathrm{H}$ and $13 \mathrm{C}$ NMR spectroscopic data for compound (11).

\section{How to cite}

ALEXANDRE GP, SIMÃO JLS, TAVARES MOA, ZUFFO IMS, PRADO SV, PAIVA JA, MUSTAPHA AN, OLIVEIRA AE, KATO L \& SEVERINO VGP. 2022. Dereplication by HPLC-ESI-MS and antioxidant activity of phenolic compounds from Banisteriopsis laevifolia (Malpighiaceae). An Acad Bras Cienc 94: e20201844. DOI 10.1590/0001-3765202220201844.

Manuscript received on December 1, 2020;

accepted for publication on April 16, 2021

GERSO P. ALEXANDRE ${ }^{1}$

https://orcid.org/0000-0001-9418-3706

JORGE LUIZ S. SIMÃO'

https://orcid.org/0000-0001-6177-9466

\section{MARIA OLIVIA A. TAVARES ${ }^{1}$}

https://orcid.org/0000-0002-3202-3122

IZABELLA MARIANA S. ZUFFO ${ }^{1}$

https://orcid.org/0000-0001-6353-1990

STÉPHANIE V. PRADO ${ }^{1}$

https://orcid.org/0000-0001-6230-6732

JOSEILSON A. DE PAIVA ${ }^{2}$

https://orcid.org/0000-0003-0718-8440

ABUBAKAR N. MUSTAPHA ${ }^{3}$

https://orcid.org/0000-0003-2553-2428

ANSELMO E. DE OLIVEIRA ${ }^{4}$

https://orcid.org/0000-0001-7468-8221

\section{LUCILIA KATO ${ }^{1}$}

https://orcid.org/0000-0003-1366-0764

\author{
VANESSA GISELE P. SEVERINO' \\ https://orcid.org/0000-0001-5384-6657 \\ ${ }^{1}$ Federal University of Goiás, Institute of \\ Chemistry, Avenida Esperança s/n, Campus \\ Samambaia, 74690-900 Goiânia, GO, Brazil \\ ${ }^{2}$ Federal University of Tocantins, Department of \\ Chemistry, Avenue Paraguai s/n, Campus Cimba, \\ Setor Cimba, 77824-838 Araguaína-TO, Brazil \\ ${ }^{3}$ Federal College of Education (Technical) Gusau, Department \\ of Chemistry, (SOSE), P.M.B. 1088, Zamfara State, Nigeria \\ ${ }^{4}$ Universidade Federal de Goiás, Laboratory of \\ Theoretical and Computational Chemistry, Instituto \\ de Química, 74690-900 Goiânia, GO, Brazil
}

Correspondence to: Vanessa Gisele Pasqualotto Severino

E-mail:vanessapasqualotto@ufg.br

\section{Author Contributions}

G.P.A. and J.L.S.S. were responsible for dereplication studies, conceptualization, and writing the original draft; M.O.A.T., I.M.S.Z. and S.V.P. were responsible for chemical studies of the ethanolic extracts of the flowers and for conceptualization and editing; J.A.P and L.K were responsible for mass and NMR analyses and chemical characterization; A.E.O. was responsible for PCA, HCA, writing, and editing; A.N.M. was responsible for writing the original draft, editing, and review; V.G.P.S. was responsible for investigation, conceptualization, project administration \& management, and writing the original draft.

\section{(cc) BY}

